\title{
Minería y cercamientos hídricos en el páramo andino
}

Recibido: 12/05/2021

Aprobado: 02/08/2021
HÉCTOR LÓPEZ TERÁN

Universidad Nacional Autónoma de México (UNAM)

hector.teran@comunidad.unam.mx

https://orcid.org/0000-0001-7195-8038

\section{RESUMEN}

El presente trabajo analiza la apropiación y la concentración de agua en la extracción de yacimientos minerales en el páramo andino. En el proceso de desposesión territorial subyace la apropiación, concentración y delimitación de agua para la extracción de minerales que restringe e impide su fluidez para el desenvolvimiento de actividades — materiales y simbólicas - productivas y consuntivas. En este sentido, el análisis expone el control y dominio del agua subyacente en el proceso de desposesión de la actividad minera en el páramo andino como vía de usurpación del bien común e imposición del metabolismo social hegemónico en función de la acumulación de capital y en contra de los medios y modos de vida de las comunidades vinculadas al páramo y el agua.

Palabras clave: minería, agua, acumulación por desposesión, cercamientos

\section{Mining and water enclosures in the Andean Páramo}

\begin{abstract}
This paper analyzes the water appropriation and concentration in the extraction of mineral deposits in the Andean Páramo. Behind the process of territorial dispossession lies the appropriation, concentration, and delimitation of water used for mineral extraction that restricts and prevents its flow for everyday activities -material and symbolic- aimed at production and consumption. In this sense, the analysis exposes the underlying control and domination over water in the process of dispossession caused by mining activity, in the Andean Páramo, as a way of usurping the common good and imposing the hegemonic social metabolism in terms of capital accumulation and opposing the means and ways of life of the communities linked to the páramo and water.
\end{abstract}

Keywords: mining, water, accumulation by dispossession, enclosures 
H presente trabajo analiza el cercamiento de fuentes hídricas como un proceso subyacente en la desposesión y el cercamiento territorial empleado para la extracción de minerales y sus consecuencias en el entorno socialnatural de comunidades —indígenas y campesinas - que suscriben la reproducción de su vida al ecosistema páramo y a la gestión del agua como bien común. Desde el análisis de los cercamientos — como regímenes de propiedad particular necesarios para la reproducción y acumulación de capital (Harvey 2004, Midnight Notes Collective 1990, Marx 2006) — entendemos que en el proceso de delimitación territorial por medio de concesiones para la explotación de minerales en el páramo andino subyace un proceso interno de despojo, apropiación y concentración de agua por las mineras para uso exclusivo de sus actividades.

El concepto de cercamientos hídricos lo empleamos para comprender la expropiación, apropiación y concentración de agua como bien privado que transgrede su valor de uso por el valor de cambio al trasmutar su régimen de propiedad, su gestión y su uso. Dicho concepto lo ubicamos a partir del análisis de las actividades mineras en el páramo andino ${ }^{1}$ principalmente a través del seguimiento de proyectos mineros en Cajamarca (Perú) y Azuay (Ecuador), y los conflictos por el agua entre las empresas mineras y las comunidades. En el páramo andino subyacen cercamientos de agua para uso exclusivo de la actividad minera como un proceso inherente y encubierto al proceso de cercamiento territorial ${ }^{2}$ que conlleva el uso exclusivo de agua. Esto se da a partir del trastocamiento de un régimen de propiedad sustentado en la colectividad a un régimen productivo centrado en la propiedad privada en función del control y la valorización crematística de la naturaleza.

Al cambiar el régimen de propiedad y su uso, cambia la relación metabólica social-natural (Marx 2006, Schmidt 2012) de las comunidades vinculadas al páramo que emplean el agua en actividades productivas y consuntivas, al limitar y restringir su uso al proceso productivo de minerales. En dicho proceso - de manera paralela — subyace la imposición hegemónica de un modo de vida particular en el que el agua se convierte en un recurso económico y deja de ser un bien común. El cercamiento limita el uso e impone el metabolismo del capital (Bellamy 2004, Toledo 2013, Marx 2006, Schmidt 2012) por me-

1 Ecosistema extendido desde Mérida, Venezuela, hasta el norte del Perú.

2 Los cercamientos hídricos no son exclusivos de la actividad minera en los páramos, pueden presentarse en territorios potenciales de extracción a gran escala que requieren en su proceso productivo de agua. En el presente trabajo exponemos los cercamientos de agua desde el contexto del páramo andino y la minería metálica a gran escala. 
dio de la explotación minera, al tiempo que restringe otros procesos metabólicos de modos de vida distintos vinculados a la naturaleza y su valor de uso.

En este sentido, a partir de las reflexiones realizadas segmentamos el presente trabajo en tres apartados. El primero, aborda el concepto de metabolismo social para comprender la relación social-natural en la reproducción de la vida humana en diferentes escalas y distintas formas de apropiación de la naturaleza, su modificación en tiempo y espacio, y su carácter no totalizante en espacios disuadidos por la hegemonía del capital. En este caso, en el páramo - previo a la expansión de la actividad minera - se gestiona un proceso social-natural con características propias que ha vinculado a las comunidades y la naturaleza — que conjunta una dinámica natural y otra social— en una unidad que configura el territorio y la gestión de sus bienes. El segundo apartado analiza el trastocamiento ecológico y social de la minería a gran escala en el páramo al ser un ecosistema sensible por sus condiciones biológicas y gran reservorio de agua. El tercer apartado describe el proceso de cercamientos hídricos como un proceso impositivo y dominante de concentración de agua inherente al despojo de territorios para el funcionamiento de las actividades mineras y la reproducción de capital. Por último, se esbozan algunas reflexiones sobre las repercusiones sociales y ecológicas del cercamiento de agua.

\section{Metabolismo social y páramo}

Siguiendo el trabajo de Bellamy (2004), Marx (2006) entiende el concepto de metabolismo social (stoffwechsel) desde dos perspectivas: la primera, refiere a la interacción social-natural por medio del trabajo humano real, y la segunda, a las necesidades y las relaciones alienadas generadas y reproducidas por el capitalismo (Bellamy 2004). El concepto suscribe un proceso histórico y social, que, aunque pareciera totalmente dilatado por la dinámica global del capital, la relación social-natural no es totalizadora y homogénea en la reproducción global (Toledo 2013). En espacios locales subyacen comunidades con vínculos estrechos con la naturaleza, con su ecosistema circundante y sus bienes comunes, que organizan un entramado social-natural diferente a la reproducción moderna sustentada en la dominación de la naturaleza y el ser humano (Galafassi 2009, Acsebrud 2012, Toledo 2013, Machado y Rossi 2017)»plainCitation»:»(Galafassi 2009; Acsebrud 2012; Toledo 2013; Machado Aráoz y Rossi 2017. 
En la zona de alta montaña de los Andes sudamericanos encontramos un metabolismo social particular configurado a partir de la interrelación de las comunidades indígenas y campesinas con el ecosistema páramo ${ }^{3}$ y el agua. Dicha configuración es posible debido a que el ecosistema páramo tienen funciones naturales (biológica e hidrológica) y sociales (cultural y social) (Medina y Mena 2001, Mena 2009, Mena 2001) que le permiten eslabonar la interacción social-natural. Dentro de la función natural, la función biológica de los páramos deriva de la composición de sus suelos andosoles con altas propiedades de porosidad, humedad y alta retención de agua y permeabilidad, y la función hidrológica procede de la capacidad de regulación hídrica, de la retención y liberación de agua hacia cuencas hidrológicas ${ }^{4}$ (Mena 200, Podwojewsk y Poulenard 2011; De Bièvre, Iñiguez, y Buytaert 2011). Las características geológicas y los altos niveles de pluviosidad forman suelos húmedos similares a esponjas que recolectan y distribuyen agua que, en primera instancia, sirve de gran reservorio, y en segunda, de suministro para actividades agrícolas, ganaderas y consuntivas de poblaciones que habitan montaña abajo en zonas rurales o urbanas. ${ }^{5}$ Además, en términos ambientales, los páramos son un gran sumidero de carbono (De Bièvre, Iñiguez, y Buytaert 2011; Mena 2009; Molina 2011; Podwojewsk y Poulenard 2011).

El vínculo de las comunidades con el ecosistema y el agua genera la función social que deriva en las expresiones sociales y culturales a partir de la interacción material y simbólica. Los páramos históricamente han sido ecosistemas de generación de vida, cerca de las áreas de fluidez del agua se han asentado comunidades rurales que configuran una relación estrecha con el ecosistema y el agua a partir de gestionar el uso del agua como un elemento vital para las actividades productivas y consuntivas (Recharte y Gearheard 2001), así como simbólicas que derivan en significaciones e identificaciones como la «cultura paramera» (Medina y Mena 2001) y la filosofía andina

3 Los páramos son ecosistemas naturales ubicados en alta montaña sobre la franja equinoccial del planeta considerados como un gran humedal y reservorio de agua por su capacidad natural de almacenamiento. En Sudamérica, los páramos se ubican en las regiones norte y central de los Andes entre los $3000 \mathrm{~m} \mathrm{~s}$. n. m. y los 5000 m s. n. m., desde Mérida, Venezuela, hasta el Huancabamba, en el norte de Perú. Por su capacidad de almacenamiento de agua, es considerado un gran humedal (De Bièvre, Iñiguez, y Buytaert 2011; Podwojewsk y Poulenard 2011).

4 Para Medina y Mena (2001), los páramos son almacenadores y reguladores del volumen de agua de lluvia formada por el choque de dos aires húmedos provenientes del occidente y oriente de la cordillera que suben hasta el páramo en forma de nubes o neblina y se precipitan en los suelos, generando una gran esponja.

5 Para Medina y Mena (2001), los páramos son almacenadores y reguladores del volumen de agua de lluvia formada por el choque de dos aires húmedos provenientes del occidente y oriente de la cordillera que suben hasta el páramo en forma de nubes o neblina y se precipitan en los suelos, generando una gran esponja. 
(Pichicasa y Guamán 2011). Desde tiempos precolombinos existe un vínculo estrecho con el páramo como suministro de agua que ha generado un indivisibilidad social-natural de las comunidades con el páramo al compartir un elemento sustancial para la vida (Manosalvas 2012, Vélez Galeano 1999).

La relación de la sociedad con la naturaleza tiene un carácter transhistórico que no puede obnubilar el impacto de la acción de los seres humanos en su interacción con la naturaleza (Schmidt 2012, Marx 2006, Bellamy 2004). Sin embargo, las interacciones en la relación social-natural devienen en distinto niveles de impacto y de las formas particulares de interacción ser humanonaturaleza. En el páramo, por ejemplo, la intervención antrópica por medio de la ganadería, la agricultura, la plantación de especies ajenas y la actividad minera producen diversos disturbios que alteran en magnitud sus servicios ecológicos al ser un ecosistema frágil, más que por la repercusión natural generada por la erosión del suelo, las lluvias, las heladas, los animales, etc. (Vargas 2013). Entre la actividad productiva de las comunidades indígenas y campesinas y la actividad productiva minera existe una brecha amplia que distingue dos modelos distintos de relacionamiento con la naturaleza y dos esquemas metabólicos con niveles de impactos ecológicos distintos que devienen en la forma en que interactúan las comunidades y las mineras con la naturaleza. En la relación comunidad-páramo existe un proceso de apropiación de la naturaleza entre los pobladores que (co)habitan con el ecosistema por el constante diálogo que permite el mutuo cuidado, resguardo y alteración mínima desde el proceso de coevolución; mientras la relación minería-páramo suscribe un proyecto modernizador de dominio, control y explotación de la naturaleza aplicado por medio de las viejas prácticas de cercamientos que expropian, apropian y concentran la naturaleza para la extracción de minerales en función de la acumulación de capital (Harvey 2004, Midnight Notes Collective 1990, Perreault 2013).

\section{Minería, páramo y agua}

En las áreas de ecosistema páramo de la región andina se encuentran distintos proyectos mineros ${ }^{6}$ para la extracción de minerales como el oro, la plata y el cobre que circundan ecosistemas por medio del despojo y subsumen valores

6 Para mayor referencia sobre proyectos mineros y conflictos, puede revisarse EJOLT (Mapping Environmental Justice), disponible en el siguiente enlace: http://www.ejolt.org/. 
de uso para extraer ganancias a través de la explotación de la naturaleza articulada a la dinámica del mercado mundial. En este sentido, los páramos al representar un ecosistema caracterizado por sus funciones naturales y sociales se convierten en territorios en disputa por los minerales y el agua (Manosalvas 2012). En países como Ecuador y Perú, la expansión de la minería en los páramos ha incrementado la extensión de territorios concesionados para extraer minerales por medio de minas a cielo abierto en zonas de recarga hídrica con el objeto de perpetuar un modelo económico cortoplacista sustentado en el crecimiento y desarrollo económico limitado en absorción laboral, escaso impacto económico y ecológicamente destructivo (Budds y Hinojosa 2012, Carrera 2018, Molina 2011, Gómez y Eschenhagen 2014, Sánchez 2017, Svampa 2019, Svampa y Viale 2014). Al insertarse la minera en un ecosistema frágil, los proyectos mineros representan una amenaza directa hacia la naturaleza, un proyecto de muerte (Toledo 2016) propio del neoextractivismo (Acosta 2011, Gudynas 2009, Svampa 2012) que amenaza los suelos y las fuentes de agua. Los disturbios altamente destructivos y dañinos para el ecosistema pueden devastar la dinámica hidrológica, limitar la capacidad de almacenamiento de agua en los suelos, contaminar el agua por el uso de químicos en los procesos de lixiviación, e impactar en la biodiversidad y en la dinámica económica, social y cultural de las comunidades (Vargas 2013).

Las prácticas mineras irrumpen en el páramo de manera negativa al ser intensivas en la destrucción de la naturaleza en proporción a la cantidad de minerales extraídos y al uso de energía y materiales utilizados (Acosta y Sacher 2011, Budds y Hinojosa 2012, Gómez y Eschenhagen 2014, Sánchez 2017, Sosa 2012). La actividad minera se concentra en procesos intensivos de explotación a cielo abierto con alta tecnología para extraer minerales de yacimientos de difícil acceso mediante una composición orgánica del capital de las mineras en alto capital fijo y bajo capital constante; es decir, mayor nivel en maquinaria y tecnología y menor fuerza de trabajo. Además, la minería a gran escala suscribe una conexión con los grandes capitales financieros para la construcción de proyectos mineros altamente costosos (Harvey 2004).

La minería amenaza el ecosistema páramo. Los procesos productivos de extracción de minerales aumentan la asimetría sociedad-naturaleza y complejizan el intercambio mutuo, subyacente históricamente, por el alto impacto ecológico y social (Acosta 2011, Delgado 2010, Machado 2020, Machado y Rossi 2017). La inserción de la minería trastoca el metabolismo social del territorio y las comunidades cercanas al alterar su organización social, econó- 
mica y cultural; modifica el entorno social y el relacionamiento con su ecosistema, al tiempo que convierte el territorio - rico en valores de uso- en un territorio de sacrificio (Svampa y Viale 2014), que amenaza el agua y la función social-natural de organización colectiva de comunidades. El desplazamiento territorial y social circunda áreas naturales, organizaciones, instituciones, culturas y subjetividades con la expropiación de territorios en función de la reproducción de capital (Acsebrud 2012, Galafassi 2009, Machado 2013, Machado y Rossi 2017, Svampa y Viale 2014)»plainCitation»:»(Acsebrud 2012; Galafassi 2009; Machado Aráoz 2013; 2020; Machado Aráoz y Rossi 2017; Svampa y Viale 2014.

En el proceso de trastocamiento subyace el despojo representativo de una economía de rapiña (Machado 2020), la expropiación de territorios comunes - por la fuerza y la violencia - para convertirlos en propiedad privada al suscribirse como elementos imprescindibles del proceso de acumulación y reproducción de capital (Midnight Notes Collective 1990, Harvey 2004, Marx 2006). A la expropiación territorial por medio de concesiones de suelos ricos en minerales le acompaña la anexión de concesiones de fuentes hídricas que son utilizadas como insumos de la actividad productiva minera, principalmente en el proceso de lixiviación. El agua se agrega con un sentido de propiedad que delimita su uso exclusivo para las actividades mineras, pero con restricción y desabasto para las comunidades cercanas; es decir, adquiere un carácter económico de mercado, al tiempo que - como afirma Manosalvas (2012) - representa un carácter político de contestación porque en ella subyacen relaciones sociales de dominación, instauradas por la dinámica del mercado y el capital, hacia la naturaleza y las comunidades.

El agregado natural en el cercamiento de los territorios de extracción minera conlleva la apropiación y la expropiación extraordinaria de recursos hídricos con valor de uso dispuestos a ser integrados al proceso de reproducción de capital. Esto quiere decir que existe — dentro de un área delimitada - cercamientos internos que se apropian de los recursos ubicados — dentro de la delimitación del territorio despojado - potencialmente incorporables como insumos en el proceso productivo de extracción de minerales (Perreault 2013, Acosta 2010). En este sentido, en la actividad minera en los páramos subyace una apropiación de suelos ricos en minerales y de recursos hídricos manifiesta —en los proceso de desposesión (Harvey 2004) — que genera tensiones y disputas entre las comunidades y las mineras por el agua y el territorio (Budds 
y Hinojosa 2012, López 2018, Manosalvas 2012, Martínez 2012, Roa 2020, Sosa 2012, Acevedo y Correa 2017).

\section{Cercamientos hídricos y concentración del agua}

En el proceso de despojo del territorio para explotar yacimientos minerales sucede el proceso de apropiación y concentración de agua para integrarla al proceso productivo minero. La minería requiere grandes cantidades en su proceso productivo, por ende, mantiene cercanías con fuente hídricas de los páramos para solventar la demanda. Las mineras aseguran el abastecimiento de agua mediante el cercamiento, trastocando el uso y el régimen de propiedad de las fuentes hídricas de los páramos. En este caso, sucede como afirma Altvater (2014) un proceso de apropiación de la naturaleza como recurso valorizable para beneficio económico particular al establecer la propiedad privada sobre la naturaleza como elemento fundamental en el proceso productivo de reproducción de capital.

El cercamiento hídrico modifica la propiedad y su uso del agua de manera unidireccional; la circunscribe a un insumo para la producción. El proceso de apropiación de agua, limitada y exclusiva como cercamiento hídrico para la minería, restringe la fluidez de los depósitos y escorrentías para actividades de solvencia cotidiana como la agricultura y la ganadería, además, inactiva su uso por los efectos contaminantes (Acosta 2010; Budds y Hinojosa 2012; Isch 2011; 2012; Perreault 2014; 2013). Por un lado, destruir el suelo que permite el almacenamiento de agua y contaminar con metales pesados aguas superficiales o subterráneas restringe el flujo del agua al disminuir el suministro, limita el consumo humano e imposibilita la reproducción de la vida. Y, por otro lado, la concentración de agua, la disminución del flujo y la desertificación de cuencas hidrográficas afectan el entorno de las actividades productivas agrícolas y ganaderas, muchas de ellas de soberanía alimentaria, restringen la autonomía en sus actividades productivas y condicionan formas comunitarias de gestión y gobernanza.

El despojo del bien más preciado para la reproducción de la vida de las comunidades, representa la modificación de un régimen de propiedad que restringe sus derechos de uso (Beccar, Boelens, y Hoogendam 2007), sus formas de apropiación, intercambio, consumo, e impone la subjetividad crematística de la naturaleza como recurso mercantilizable. El cercamiento delimita la vida 
impuesta por medio de un régimen de servidumbre que suscribe al páramo a fuente de recursos de explotación, provocando cambios en la reproducción material e inmaterial de los pobladores. Transgredir el uso de agua construido históricamente por las comunidades impone la hegemonía de dominación de la naturaleza en función de lo productivo y lo rentable, al tiempo que restringe modos de vida alternativos que asumen el agua como eje fundamental para el desenvolvimiento cotidiano.

La minería trastoca las actividades de los pobladores que emplean el agua en sus actividades productivas y consuntivas y resquebraja los cimientos de sus representaciones simbólicas y sacras; además, destruye y agota los recursos hídricos. La relación sujeto-agua, producto de la cualidad «híbrida» del agua de los pobladores (Swyngedouw 2004, 28; citado por Isch 2012, 23), se diluye al insertarse un proceso mercantil de apropiación del bien colectivo. Las comunidades pueden verse afectadas en el cambio de sus actividades de trabajo agrícolas y ganaderas, en la merma en sus funciones por el agotamiento de agua, en el trastocamiento de nuevas fuentes de solvencia económica y en la pérdida de sus fuentes de trabajo. Muchas de las comunidades, si bien habitan montaña abajo, ven afectados sus cultivos y ganado ante la falta de suministro y su consumo doméstico y de alimentación. Cambiar el régimen de agua despoja a las poblaciones de sus territorios y de sus medios de vida obligándolos a desplazarse hacia otros sectores para buscar los medios necesarios para solventar la vida.

Acsebrud (2012) menciona que, en el momento en que se impone la perspectiva capitalista de acumulación en poblaciones locales, se altera la situación social, económica y cultural de territorio, produciendo un cambio en las formas de vida, la producción del espacio y la transformación de la naturaleza (Acsebrud 2012). Concentrar el agua para uso productivo minero representa una envestida violenta, en el sentido no exclusivo del despojo de los territorios y de la población, al amenazar con suprimir la naturaleza y modos de vida ligados al páramo y al agua (Roa y Urrea 2010) ante la imposición de la lógica de reproducción de capital por medio de la valorización de la naturaleza y de la vida. Este enfrentamiento es una acción directa que confronta y pone en un campo en tensión dos formas de interacción en la unicidad ser humano-naturaleza, dos formas de metabolismo social manifiestas en dos valoraciones distintas del agua como insumo productivo o mercancía o como bien común. 
Por consiguiente, la minería irrumpe y condiciona la vida social-natural de las poblaciones vinculadas al páramo y al agua, y el cercamiento hídrico la profundiza al suprimir la propiedad colectiva del agua y su valor de uso. Cercar el agua también implica, por un lado, delimitar —impositivamenteun modo determinado de vivir al forzar el uso del agua a la producción minera, al restringir el acceso al recurso y al imposibilitar su uso; y, por otro lado, inserta la lógica de dominio y control de la naturaleza para fines de reproducción de capital sobre la base de un trastocamiento de un régimen de propiedad, gestión y gobernanza del agua.

\section{Reflexiones finales}

La extracción minera a gran escala suscita consecuencias en múltiples escalas que atraviesan lo económico, social y ecológico. La explotación de la naturaleza disemina la dinámica del metabolismo social del capital mediante la apropiación y la expropiación de los bienes comunes a través de cercamientos que imponen el dominio y el control de la naturaleza para su mercantilización. Como sucede en los procesos de extracción minera en el páramo andino, la delimitación exclusiva y restringida de un área explotable permite la explotación de riquezas naturales consideradas como recursos y al mismo tiempo el uso de naturaleza como insumo necesario para el proceso productivo. La apropiación y expropiación profundiza la delimitación territorial de explotación de yacimientos al expandirse hacia los bienes comunes demandados en el proceso de producción de minerales, concentrándolos y acaparándolos como recursos útiles para las mineras mediante el control en su acceso y uso.

La actividad minera en el páramo andino ilustra el proceso de concentración de territorio y agua en la explotación de minerales y la modificación de la relación social-natural de las comunidades. El cercamiento territorial asegura los depósitos de minerales, mientras que el cercamiento del agua, el abastecimiento de la demanda hídrica necesaria para el proceso productivo; ambos trastocan el metabolismo social integral de las comunidades con la función natural y social del páramo, al tiempo que imponen el metabolismo social del capital.

La amenaza minera deviene en un campo en tensión expreso en las luchas contra el despojo, la concentración y la gestión del agua. Las comunidades - con otro modo de apropiación y vinculación con el páramo y el agua- 
expresan un modo particular de vivir que resiste y crea alternativas ante la intensión hegemónica de imponer la minería en zonas de recarga hídrica. La explotación de los páramos y la concentración del agua para uso exclusivo minero representan una amenaza a una fuente importante de vida en el sur del continente. Devastar las zonas de recarga hídrica y las escorrentías que descienden desde lo alto de la montaña limitaría la reproducción de la vida por el agotamiento del recurso vital y por la pérdida de comunidades que viven en relación al páramo y al agua. 


\section{Referencias bibliográficas}

Acevedo Tarazona, A. y Correa Lugos, A. 2017. Páramo de oro: neoextractivismo y movilización social ambientalista en Santurbán. Revista Controversia, (208), 193-221.

Acosta, A. 2010. El agua, un derecho fundamental. En Martínez, E. y Acosta, A. (Eds.). Agua. Un derecho fundamental (pp. 7-45). Quito: Ediciones Abya-Yala.

Acosta, A. 2011. Extractivismo y neoextractivismo: dos caras de la misma maldición. En Lang, M. y Mokrani, D. (Eds.). Más allá del desarrollo (pp. 83-118). Quito: Fundación Rosa Luxemburgo, Ediciones Abya-Yala.

Acosta, A. y Sacher, W. 2011. El agua de Quimsacocha, entre la codicia y la vida. Rebelión (blog). https://n9.cl/q18ou.

Acsebrud, E. 2012. Espacios particulares de acumulación en relación a la megaminería metalífera a cielo abierto. Theomai, (25), 102-12.

Altvater, E. 2014. El capital y el Capitaloceno. Mundo Siglo XXI, Revista del CIECAS$I P N, I X(33), 5-15$.

Beccar, L., Boelens, R. y Hoogendam, P. 2007. Derechos de agua y acción colectiva en el riego comunitario. En Boelens, R. y Hoogendam, P. (Eds.). Derechos de agua y acción colectiva (pp. 21-45). Lima: Instituto de Estudios Peruanos, WALIR.

Bellamy Foster, J. 2004. La ecología de Marx. Materialismo y naturaleza. Madrid: Ediciones de Intervención Cultura, El Viejo Topo.

Budds, J. y Hinojosa, L. 2012. Las industrias extractivas y los países hídricos en transición en los países andino: análisis de la gobernanza de recursos y formación de territorios en Perú. En Isch, E., Boelens, R. y Peña, F. Agua Injusticia y conflictos (pp. 45-61). Lima: Justicia Hídrica, Centro de Estudios Regionales Andinos Bartolomé de las Casas, Instituto de Estudios Peruanos.

Carrera, J. 2018. El papel de la financierización en la dinámica de los precios de los productos básicos. En Martín, A., Pérez Caldentey, E. y Valdecantos, S. Estudios sobre Financierización en América Latina (pp. 227-270). Santiago de Chile: Naciones Unidas.

De Bièvre, B., Iñiguez, V. y Buytaert, W. 2011. Hidrología del páramo: importancia, propiedades y vulnerabilidad. En Mena, P., Castillo, A., Flores, S.,... Galo, M. (Eds.). Páramo. Paisaje estudiado, habitado, manejado e institucionalizado (pp. 81-97). Quito: EcoCiencia, Ediciones Abya Yala, ECOBONA.

Delgado Ramos, G. C. 2010. América Latina y el Caribe como reservas estratégicas de minerales. En Ecología política de la minería en América Latina. Aspectos socioeconómicos, legales y ambientales de la mega minería. Ciudad de México: Universidad 
Nacional Autónoma de México, Instituto de Investigaciones Interdisciplinarias en Ciencias y Humanidades.

Delgado Ramos, G. C. 2012. Metabolismo social y minería. Ecología Política, (43), 16-20.

Galafassi, G. 2009. La predación de la naturaleza y el territorio como acumulación. Revista Herramienta, (42).

Gómez Montes, I. G. y Eschenhagen, M. L. 2014. Conflictos socioambientales de la minería del oro y el rol del modelo económico dominante en América Latina. En Göbel, B. y Ulloa, A. (Eds.). Extractivismo minero en Colombia y América Latina (pp. 389423). Bogotá, Berlín: Universidad Nacional de Colombia, Ibero-Amerikanisches Institut.

Gudynas, E. 2009. Diez tesis sobre el nuevo extractivismo. Contexto y demandas bajo el progresismo sudamericano actual. En Extractivismo politica y sociedad (pp. 187225). Quito: Centro Andino de Acción Popular (CAAP), Centro Latinoamericano y Ecología Social (CLAES).

Harvey, D. 2004. El nuevo imperialismo. Madrid: Ediciones Akal.

Isch, E. 2011. La contaminación del agua como proceso de acumulación. En Boelens, R., Cremers, L. y Zwarteveen, M. (Eds.). Justicia hídrica: acumulación, conflicto y acción social (pp. 97-109). Lima: Instituto de Estudios Peruanos.

Isch, E. 2012. Justicia hídrica: una sistematización conceptual introductoria. En Isch, E., Boelens, R. y Peña, F. (Eds.). Agua, injusticia y conflictos (pp. 21-43). Lima: Justicia Hídrica, Centro de Estudios Regionales Andinos Bartolomé de las Casas, Instituto de Estudios Peruanos.

López Terán, H. R. 2018. Vivir la contradicción: sujetidad alternativa con el agua en la modernidad capitalista [tesis de maestría]. Quito: FLACSO-Ecuador. http://hdl. handle.net/10469/14645.

Machado Aráoz, H. 2013. Orden neocolonial, extractivismo y ecología política de las emociones. RBSE-Revista Brasileira de Sociología da Emoção, 12(34), 11-43.

Machado Aráoz, H. 2020. La minería colonial y las raíces del Capitaloceno: habitus extractivista y mineralización de la condición humana. AMBIENTES. Revista de Geografía e Ecología Política, 2(1), 65.

Machado Aráoz, H. y Rossi, L. J. 2017. Extractivismo minero y fractura sociometabólica. El caso de Minera Alumbrera Ltd., a veinte años de explotación. RevIISE. Revista de Ciencias Sociales y Humanas, 10(10), 273-86.

Manosalvas, R. 2012. Las demandas campesinas frente a las demandas de la ciudad y de la industria: Luchas por el agua en el páramo de Cayambe en el Ecuador. En Isch, E., Boelens, R. y Peña, F. (Eds.). Agua, injusticia y conflictos (pp. 95-106). Lima: 
Justicia Hídrica, Centro de Estudios Regionales Andinos Bartolomé de las Casas, Instituto de Estudios Peruanos.

Martínez Allier, J. 2012. Quimsacocha: mendigos sentados en un saco de oro (7 de octubre). https://n9.cl/q4g73.

Marx, C. 2006. El capital. Crítica de la economía política. Ciudad de México: Fondo de Cultura Económica.

Medina, G. y Mena, P. 2001. Los páramos en Ecuador. En Mena, P., Medina, G. y Hofstede, R. (Eds.). Los páramos del Ecuador: particularidades, problemas y perspectivas (pp. 1-24). Quito: Ediciones Abya-Yala, Proyecto Páramo.

Mena, P. 2009. El estado de salud de los páramos en el Ecuador. En Mena, P., Vásconez, P., Morales, M., Ortiz, P.,..., De la Cruz, R. (Eds.). Gente y ambiente de páramo: realidades y perspectivas en el Ecuador (pp. 23-39). Quito: EcoCiencia, Ediciones Abya-Yala.

Mena, V. 2001. Prácticas sociales, uso de los recursos y percepciones sobre la naturaleza. ala, Proyecto Páramo. En Mena, P., Medina, G. y Hofstede, R. (Eds.). Los páramos del Ecuador: particularidades, problemas y perspectivas (pp. 89-119). Quito: Ediciones Abya-Yala, Proyecto Páramo.

Midnight Notes Collective. 1990. The New Enclosures. Midnight Notes, 10 (septiembre), $1-9$.

Molina Roa, J. A. 2011. Minería en los páramos de Colombia y la construcción de una conciencia ecológica: hacia la búsqueda de la justicia ambiental. Ecología Política, (41), 74-81.

Perreault, T. 2013. Dispossession by Accumulation? Mining, Water and The Nature of Enclosure on the Bolivian Altiplano. Antipode, 45(5), 1050-1069.

Perreault, T. 2014. Agua, minería, modos de vida y justicia social en el altiplano boliviano. En Perreault, T. (Ed.). Minería, agua y justicia social en los Andes: Experiencias comparativas de Perú y Bolivia (pp. 101-123). Cusco: Justicia Hídrica, Centro de Estudios Regionales Andinos Bartolomé de las Casas.

Pichicasa, M. y Guamán, C. 2011. La gestión andina de los páramos: el caso de Patococha, Cañar, Ecuador. En Mena, P., Castillo, A., Flores, S.,... Galo, M. (Eds.). Páramo. Paisaje estudiado, habitado, manejado e institucionalizado (pp. 173-185). Quito: EcoCiencia, Ediciones Abya Yala, ECOBONA.

Podwojewsk, Pascal, y Jerome Poulenard. 2011. «Los suelos de los páramos en Ecuador». En Mena, P., Castillo, A., Flores, S.,... Galo, M. (Eds.). Páramo. Paisaje estudiado, habitado, manejado e institucionalizado (pp. 63-80). Quito: EcoCiencia, Ediciones Abya Yala, ECOBONA. 
Recharte, J. y Gearheard, J. 2001. Los páramos altamente diversos del Ecuador: ecología política de una ecorregión. En Mena, P., Medina, G. y Hofstede, R. (Eds.). Los páramos del Ecuador: particularidades, problemas y perspectivas (pp. 55-85). Quito: Ediciones Abya-Yala, Proyecto Páramo.

Roa Avendaño, T. 2020. Época de resistencias al extractivismo. Re-visiones, (10), 4.

Roa Avendaño, T. y Urrea, D. 2010. Aguas en movimiento. Cultura y derechos. En Martínez, E. y Acosta, A. Agua. Un derecho fundamental (pp. 25-28). Quito: Ediciones Abya-Yala.

Sánchez Albarrán, A. 2017. Territorio, extractivismo y (des)ciudadanía en América Latina. El Cotidiano, 201 (febrero), 17-26.

Schmidt, A. 2012. El concepto de naturaleza en Marx. Madrid: Siglo XXI Editors.

Sosa Landeo, M. 2012. La influencia de la gran minería en Cajamarca y Apurímac, Perú: acumulación por despojo y conflictos por el agua. En Isch, E., Boelens, R. y Peña, F. Agua, injusticia y conflictos (pp. 63-79). Lima: Justicia Hídrica, Centro de Estudios Regionales Andinos Bartolomé de las Casas, Instituto de Estudios Peruanos.

Svampa, M. 2012. Pensar el desarrollo desde América Latina. En Massuh, G. (Ed.) Renunciar al bien común. Extractivismo y (pos)desarrollo en América Latina (pp. 17-58). Buenos Aires: Mardulce.

Svampa, M. 2019. Las fronteras del neoextractivismo en América Latina: conflictos socioambientales, giro ecoterritorial y nuevas dependencias. Berlín: Transcript Verlag.

Svampa, M. y Viale, E. 2014. Maldesarrollo: la Argentina del extractivismo y el despojo. Bunos Aires: Katz Editores.

Toledo, V. M. 2013. El metabolismo social: una nueva teoría socioecológica. Relaciones. Estudios de Historia y Sociedad, 34(136), 41-71.

Toledo, V. M. 2016. Ecocidio en México. La batalla es por la vida. Ciudad de México: Grijalbo.

Vargas Ríos, O. 2013. Disturbios en los páramos andinos. En Visión socioecosistémica de los páramos y la alta montaña colombiana: memorias del proceso de definición de criterios para la delimitación de páramos (pp. 39-57). Bogotá: Ministerio del Ambiente y Desarrollo Sostenible.

Vélez Galeano, H. 1999. Es tiempo de agua viva. Nuestra experiencia en el páramo. En Flórez, M. (Ed.). Agua pasó por aquí: experiencias sociales de manejo sostenible. Una alternativa a la privatización (pp. 139-154). Bogotá: ILSA, ITEM. 